\title{
Mis keeles me räägime loomadega ${ }^{1}$
}

\begin{abstract}
Mare Kõiva
Teesid: Sotsiaalkultuurilise ja majandussääri muutused kajastuvad folklooris stereotüüpide, uskumuste, eelarvamuste ja teatud narratiiviliikide elavnemisega. Lemmikloomade arvukuse kasv annab põhjuse vaadelda inimese ja looma kommunikatsiooni erijooni, samuti keelekasutuse liike. Artiklis on seda tehtud folklooritekstide ja küsitlustulemuste vahendusel. Loomaomanikud kasutavad tavalise või kergelt lihtsustatud keele kõrval lastekeelt ja vajadusel koodivahetust. Koodivahetus edastab hoiakuid ja aitab saavutada soovitud erilise efekti (premeerimine, laitus, allutamine). Verbaalse suhtlemise kõrval on tähtis roll mitteverbaalsel kommunikatsioonil ja mitme suhtlemisviisi kombineerimisel. Suhtlemissituatsiooni kajastavatest folklooriliikidest on püsinud tänaseni kasutusel universaalsed mitteverbaalsed signaalid (vilega kutsumine ja peletamine, häälitsuse imitatsioonid) ja lihtsad kutsungid ehk siis instrumentaalne ja häälega signaliseerimine. Keerukamad poeetilised tekstid (loodushäälendid, karjaserepertuaari kuulunud hüüded ja kutsungid, sõnamaagilised peitenimetused, loitsud) on nihkunud institutsionaliseeritud folklooriliikumisse või professionaalide loomingusse. Elavnenud folklooriliikide hulka kuuluvad isikujutud - lihtsad narratiivivormid, mis on kultuuriliselt oluliste sõnumite kandjateks. Niisugusesse vormi on kätketud ka uskumused loomade võimest mõista inimkeelt ja käituda arukalt. Juttude funktsioonide hulka kuulub lokaalse stabiilsustunde loomine. Verbaalse suhtlemise olulisus on seotud ühiskonnas kujunenud käitumispiirangute ehk piiratud emotsionaalsete standardite ja positsioonidega. Loomadega suheldes saame vabamalt kasutada emotsioone ja määrata oma rolle. Tänapäevase loomakultuuri juurde kuuluvad tehnoloogilised tõlkevahendid ja arenev professioon - telepaatia abil tõlkijad -, mis peegeldab vajadust mõista teise poole sõnumeid.
\end{abstract}

Märksõnad: inimese ja looma kommunikatsioon, lemmikloomakultuur, loomajutud, zoofolkloor

“Mis keeles me räägime taevas?” küsib Matt Dabbs oma blogis ja pakub mitmeid vastuseid, näiteks: "Olen sageli mõtelnud, kas räägime taevas igaüks omas keeles ja kuuleme üksteise juttu oma emakeeles” (Dabbs 2007). Muude vastuste hulgas pakub ta ka võimaluse ühisest müütilisest keelest, mida kõik mõistavad. Sotsiolingvisti Dell Hymesi (1974) ja religiooniloolase Wade 
Wheellocki (1987) kuulsad uurimused keeltest, mida räägitakse jumalaga, osutavad teatud keelte kõrgemale staatusele võrreldes teistega, sest need on olnud piibli keeled. Religiooni seisukohast olulise keele eelistamine on tunnuslik kristluse kõrval ka teistele usunditele. Kas ja kuidas me suhtleme loomadega, eriti silmas pidades tšehhi keeleteadlase Jan Purcha postulaati, et "keelelise tegelikkuse määravad kindlad eesmärgid, programmid või sihid, mis peegeldavad sotsiaalseid vajadusi" (Prucha 1983)? Inimeste suhtlemine lemmikja inimkaaslejate loomadega on pika ajalooga, ent viimase poolsajandi oluliste muutuste tulemusena asustavad mõned metsikud liigid ise linnaruumi, teised elavad üha arvukamalt inimese hoole all kodudes. Euroopa industriaalriikide statistika osutab lemmikloomade arvu järsule kasvule: Suurbritannias oli 1995. aastal 50\% perekondadest vähemalt üks lemmikloom: 5,2 miljonit koera, 4,8 miljonit kassi, 2,7 miljonit kala, 800000 papagoid. 1997. aasta statistika Iirimaa kohta on ligilähedaselt samasugune. 2009. aasta statistika osutab, et kasse ja koeri elab kumbagi umbes 8 miljonit (pmfa 2009), rohkem kui pooltes USA peredes on lemmikloom (The Humane Society 2008), Austraalias peab lemmiklooma üle $60 \%$ peredest (PetNet 2008).

Hiljutisi muutusi iseloomustades on tavaks üldistada, et "loomadel on tänapäeval täiesti erinev sotsiaalne funktsioon" (Gustavsson 2008: 101; vrd Vesik 2008: 69 jj; Manning \& Serpell 1994; Ingold 1988; Baker 1993). Uuemad uurimused inimeste ja loomade seotusest kummutavad levinud eelarvamusi ja stereotüüpe, osutades, et loomaomanike keskmine vanus on alla 65 aasta, nad on pigem abielus kui üksikud või lesed. ${ }^{2}$ Lemmikloomi võtavad endale sagedamini lastega perekonnad, eriti sellised, kus on üle nelja liikme ja tihti on loom ühtlasi minapildi komponent (Serpell 1986, vrd pmfa 2008). Arvukad uuemad uurimused osutavad, et ôhtumaises kultuuris koheldakse lemmikloomi nagu sugulasi või perekonnaliikmeid, sotsioloogide andmetel ei ole erandlikud juhtumid, kus perekond peab oma koera lähedasemaks sugulaseks kui tädi, onu, vanavanemaid või koguni vanemaid. ${ }^{3}$ On täheldatud ka, et inimesed väljendavad lemmikloomadega suheldes ja neist rääkides rohkem emotsioone kui inimeste puhul. Rootsi uurija Anders Gustavsson üldistab: "Tegelikult väljendatakse vaimset dimensiooni looma surma puhul Rootsis palju tugevamini kui inimeste puhul" (Gustavsson 2008: 121). Eelnev osutab tähenduslikele muutustele kommunikatsioonis, sugulus- ja peresuhetes, sellest tulenevalt ka võimu-ja allumissuhtetes.

Sotsiaalkultuurilise ja majandussfääri muutused kajastuvad folklooris stereotüüpide, uskumuste, eelarvamuste, käibetõdede ja teatud narratiiviliikide elavnemisega, sest folkloor on sotsiaalselt sidus nähtus ja leiab väljenduse erinevate kommunikatsioonivormide kaudu. Folkloor on tihedalt seotud mitte üksnes muutustega ühiskonnas, vaid ka inimese dialoogilise mina arenguga. 
Eeldan, et verbaalset kommunikatsiooni mõjutavad folklooris sisalduvad uskumused, seisukohad ja teave, kuidas loomad inimkeelt mõistavad. Arvan, et osa traditsioonilistest suhtlemisviisidest püsivad vaatamata muutustele ühiskonnas ja pärimusliikide maastikul ning et suhtlemisviisis ei toimu järske kriise ja üleminekuid, vaid seda iseloomustab pigem Laozi (ka Lao Tzu, Lao Tse, Lao Tu, Laotze, Laocius jne) sõnastatud looduslik kulgemine.

Teema valiku ajendas asjaolu, et olen lapsest saadik näinud loomi ja linde kodus kasvamas ja kodu ümbruses toimetamas. Kodus, välitöödel või reisidel loomadega vesteldud tunde ja naljakaid suhtlemisseikasid on võimatu kokku arvata. Mu huvi sai toetust vestlustest Ülo Tedre, Viire Villandi ja Liisa Vesikuga ning Eesti Kirjandusmuuseumi folkloristika osakonna inimeste ja loomade suhteid analüüsivast seminarisarjast, suunates lähemalt uurima inimese ja looma kommunikatsiooni vorme ja nende muutumist ajas, kasutades folkloristika võimalusi ja osalt sotsiolingvistika meetodeid. Oma jäädvustatud intervjuude, loomulikes ja kunstlikes suhtlemissituatsioonides tehtud lindistuste kõrval arvestasin 2002. aasta on-line-konverentsi "Dialoog avaliku ja privaatse ruumi vahel" alateema "Inimesed ja loomad" (Jaago \& Kõiva 2002) foorumi vastuseid, samuti 2007. aasta koolipärimuse kogumise võistluse vastuseid lemmikloomade, nende nimede ja nendega seotud lugude kohta.

\section{Loomade kõne}

Inimmõtlemise, taju ja keele arengu alane uurimistöö on ajendanud põhjalikumalt vaatlema ka loomade kommunikatsiooni ja nende võimet mõista inimkeelt. Loomaliigid on pälvinud erinevalt tähelepanu - katsete arvu ja huvi poolest eenduvad inimesele lähemal seisvad inimahvid ja liigid, kelle signaalide mitmekesisus või õppimisvõime on tõotanud põnevaid tulemusi. Käesoleva teema puhul on kõnekad eksperimentaalpsühholoog Juan Manuel Toro uurimisrühma (2005) tulemused, mis näitasid, et mitte eriti keeleandekateks peetud rotid suudavad eristada kahte (nt jaapani ja hollandi) keelt nagu inimesed ja ahvidki. Samal ajal ei suutnud katserotid eristada samu keeli, kui need esitati tagurpidi. See Juan Manuel Toro uurimus pärjati 2007. aastal Nobeli veidrate teadussaavutuste preemiaga keeleteaduses (AIR 2007), tulemused osutavad erinevustele keele eristamise ja õppimise võimekuses.

Uuritavate liikide arvu kasvamine ja uued avastused nihutasid esiplaanile liikide kommunikatsiooni eripära. Avastused, et häälitsusi õpitakse ja see protsess kulgeb sotsiaalses süsteemis, et paljude liikide häälitsustel on individuaalne, rühma- või populatsioonispetsiifika, mis lisaks tihti reflekteerib kõnealuste isendite sotsiaalset süteemi, et loomade keelel on süntaks ja nad suudavad 
luua lauseid (Rendell 2006; Rendell \& Whitehead 2001; Reiss \& McCowan \& Marino 1997; Bradbury 2003 - papagoide häälitsused sarnanevad delfiinide häälitsustele ja erinevad laululindude omadest) on muutnud hoiakuid. Kuigi kõiki viit inimkeelele omast tunnust loomade keel ei täida, annab "kujundkõne" ja “süntaks” põhjust rääkida loomakultuurist.

Tänapäeval omandatakse teadmised looma miimika, liigutuste ja häälitsuste tähendusest tihti meedia ja vastavate erikursuste abiga, vähenenud on empiiriline iseõppimine. Loomadega räägitakse hinnanguliselt suhteliselt palju. Mu viimaste aastate küsitluste vastused võib kokku võtta järgmiselt: ${ }^{4}$

1) inimesed räägivad loomadega kas täielikku, lihtsustatud või lastekeelt sõltuvalt sellest, missuguseks nad peavad looma arusaamisvõimet. Eriolukorras, nt kiitmiseks, tähelepanu võitmiseks, õnnetuse või haiguse puhul, osalt ka oma tahtele allutamiseks kasutatakse lastekeele intonatsiooni või lühikesi lihtsama grammatilise ülesehitusega lauseid;

2) keelekoodi vahetus toimub sarnaselt inimestega suhtlemisele, st ümberlülitumised tavakõnelt lastekeelele sõltuvad suhtlemissituatsioonist;

3) osa loomaomanikke hindab oma keelekäitumist vaagides, et nad suhtlevad loomadega nagu endast nooremate või teise rühma kuuluvate või keskmise ja kehvema keeleoskusega isikute või lastega, kasutatakse ka nt salakeelt, räägitakse nt võõrkeeles, et loom ei saaks temasse puutuvast jutust aru;

4) otse loomaga rääkimist peetakse tema keelevõimekust arendavaks;

5) mitmekeelses keskkonnas kasvanud loomal arvatakse olevat mitme keele oskus.

Keelekäitumine näib sõltuvat isiku ja tema harjumuste kõrval ka keskkonnast. Vastustest ilmneb, et suhtlemisel kasutatakse meelsasti allkeeltest lastekeelt, pereringi keelestiile, mida tänaval ei peeta sobivaks. Lemmikloomaga suhtlemise juurde kuuluvad lihtsustatud lühikesed laused, objektide ja sündmuste rõhutamine, valestihääldatud või omaloodud sõnade kasutamine.

Keelekasutus on strateegiline - see võib olla premeeriv: hellitusnimed, kõrgenenud hääletoon, eriline kõnerütm, tempo jm lastekeelele tunnuslikud võtted. Keelevahendeid, sh hääletooni kasutatakse ka oma tahet kehtestades, häbistades ja karistades. Lastekeel, mida kasutatakse laste ja loomade kõrval ka armsamaga rääkides, on Eesti avalikus ruumis tabuteema - verbaalne avalik õrnutsemine on taunitav ja kuulub rangelt isiklikku ruumi. Kuna emotsionaalsed eneseväljendused ei sobi tänasesse ühiskonda, peetakse ka loomadega avalikus ruumis lastekeeles suhtlemist sobimatuks, erandiks loomaomanike ja lemmikute rühmategevused. Kõrvuti elamine ja eriti linnatingimustes eluruumide jagamine tingib, et üksteise mõistmine, nii vanade kommunikat- 
siooninippide valdamine kui ka uute õppimine on tähtsad, samas on loomade ja inimeste alluvussuhete piir õgvenenud ja suhtlemismudelid mitmekesised.

Tehnoloogiale orienteeritud maailmas on uurijatele arendatud spetsiaalne vabavara bioakustilisteks uuringuteks, loomade automaatseks häälitsuse põhjal identifitseerimiseks (Lee \& Chou \& Han \& Huang 2006), tavakodanike huvides toodetakse automaattõlkijaid. Aastal 2002 alustas Jaapani firma Takara Bowlinguali ja 2003 Meolinguali turustamist, mis tõlgib koera või kassi häälitsused inimkeelde. Revolutsiooniliselt menuka masina Ameerika versioon põrkus aga ootamatule takistusele: erinevate maade sama liiki loomadel on erinev regiolekt. Samuti ei koosne loomade keel üksnes häälitsustest, vaid sõnumi täpsustab semantiliselt kehakeel. Eesti netikommentaatorilt pälvis jaapanlaste leiutis toreda hinnangu: "Iseenesest huvitav ettevõtmine, kus tõlketehnoloogia väljub inimkõne piiridest. Äkki tasub sellisel juhul kaaluda ka vastupidise tõlkeseadme väljatöötamist, kus inimkõne tõlgitakse haukumiseks, kräunumiseks, ruigamiseks või veel millekski muuks" (Uljas 2003).

Matt Dabbsi unistusele universaalsest kommunikatsioonivormist vastab tänases ühiskonnas hobulausujate ja loitsijate liini jätkumine loomadega rääkijate kujul. Vastava maailmaorganisatsiooni juht Penelope Smith soovitab: "Mida mõtleb ja tunneb sinu koer, kass, hobune või koguni metsloom? Sa saad loomadega telepaatiliselt suheldes kasutada kõigi olendite universaalset keelt" (Smith 1997). Telepaatia abil suhtlejate ja tõlkide võrgustik on ülemaailmne,

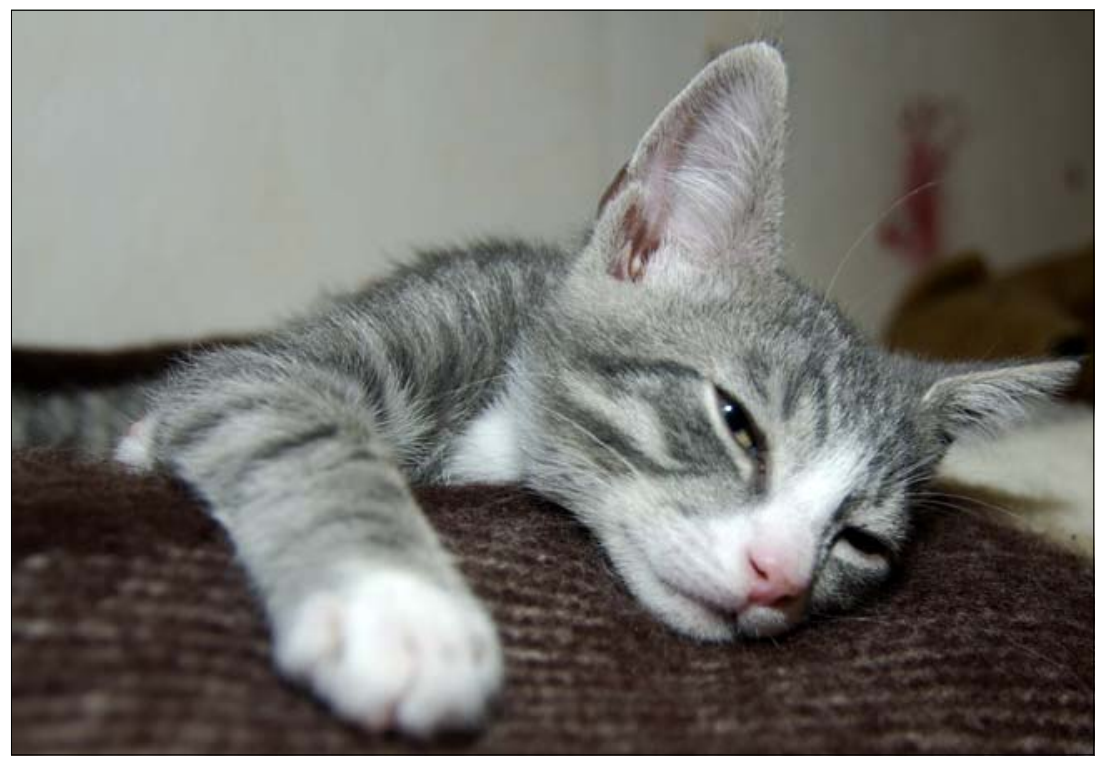

Foto 1. Triibik: Mage jutt! Foto: Andres Kuperjanov 2009. 
arvukamalt töötab neid siiski Põhja-Ameerikas. 2009. aastal intervjueeris Eesti riigitelevisioon eestlannat, kes abistab meie loomaomanikke, nii et koolkond on laienemas ka siinsesse kultuuriruumi.

\section{Varasemad arhiiviteated inimeste ja loomade kommunikatsioonist}

Paljudes folklooriliikides prevaleerib metafoori- või sümbolipõhine lähenemine, mis osutab, et kujundkõnes on inimene vajanud head võrdlusalust ja selleks sobisid loomad, keda hästi tunti. Ka poeetilistes lauludes on loomad kirjeldusobjekt või sümbol, tekstist ilmneb aimamisi, et mõni loom on olnud omanikule lähedane. Arvo Krikmann on toonud vanasõnastatistika põhjal esile olulise fakti: vanasõnades domineerivad eriti tugevasti koduloomad (isegi kütikultuuride ainestiku puhul, nagu nt jakuudid) (Krikmann 2001: 11). Sama reegel kehtib usundilistest elamustest kõnelevates juttudes. Suur hulk looma-, linnu- ja esemekujulisi olendeid toimib mediaatorina inimeste ja üleloomuliku, elavate ja surnute maailma vahel. Kummitusolendid esinevad sagedamini koera, kassi, kuke (kana), lamba, sea, lehma, hobuse kujul, enamjaolt kuradiga assotsieerub kits, vahel ka hani - koduloomad prevaleerivad metsloomade ees (Kõiva, ilmumas). Folkloorsetes kummitusjuttudes ei kohta sellist liigirikkust kui nt inglise kirjanike tuntud kummitusjuttudes (Presnakova 2010 31 liiki), vaid need on tihedalt seotud tegeliku elukeskkonnaga. Rahvaluuletekstidest ilmneb ka, et metsloomade maja juurde või koduõue tulemine, nende tee peal kohtamine oli õnnetuse enne, mida võimalusel välditi ega soovitud.

Et rahvaluule kogumise töös domineeris pikka aega liigipõhisus, saame jälgida üksnes mõnda võimalust laiemast kommunikatsioonipildist. Varasematest üleskirjutustest leiame teateid nii mets- kui ka koduloomadega suhtlemise kohta, kusjuures andmeid on instrumentaalsest, vokaalsest ja verbaalsest suhtlemisest: kasutati vilistamist, muusikainstrumente või häält (hüüded, huiked, loomahäälitsuste imitatsioonid). Verbaalse kommunikatsiooni liikidest olid tuntumad loodushäälendid, kutsungid ja loitsud. Muud kommunikatsiooniviisid ilmnevad uskumustest ja juttudest, kuid juttudes pöördutakse looma poole lühidalt. Mõnevõrra esineb neis segakeelseid fraase, kuid jutuspetsiifikast tulenevalt välditakse pikki dialooge. ${ }^{5}$

Loomi ja linde imiteeriti käepäraste algeliste instrumentidega (viled, puulehed jm) või häälega. Sellest oli praktilist kasu jahipidamisel, vahel prevaleeris maagiline eesmärk. Etnograaf Aleksei Peterson kirjeldab jahindusspetsialistile Franz Reidolfile osutades nt imitatsiooni kasutamist põdrajahil: 
Üks vana ja huvitav küttimisviis oli veel peibutusjaht. Nimelt pü̈̈ti jooksuajal põdrapulli meelitada laskeulatusse möirgamise järeleaimamisega. Tänapäeval pole vist küll ühtegi jahimeest, kes oskaks meisterlikult põdrapulli häält matkida, kuid vanasti oli. Tund aega enne päikeseloojangut mindi metsa põtrade paarimiskohtadele, mida reetsid tümaks sõtkutud maapind ja räsitud põõsad. Käidi hiilides. Hämarikus hakati häälitsema - algul tasa, hiljem valjemini ja pikemate vaheaegadega; alustati nooremale pullile iseloomulike möiratustega. Kui põder vastas, valiti kiiresti sobiv koht laskmiseks. Juhtus sedagi, et põdrapull ei võtnud kutset vastu, vaid eemaldus koos lehmaga. Sel juhul järgneti neile vastavalt häälitsedes. Selline pealetung ei peleta pulli, vaid ärritab teda, kuni ta tormab arvatava vastase suunas (Peterson \& Proodel 1968: 651).

Jahimehed orienteerusid ja pidasid metsas sidet kindlate vilede ja häälitsustega. Seda arhailist sidepidamisviisi hakati aga arhiivi jaoks fikseerima alles 1980. aastatel. Loomi ja linde imiteeriti veel segadusse ajamiseks, narrimiseks ja lihtsalt meelelahutuseks. Palju lõbu valmistas lähedale meelitamine, näiteks käo peibutamine kukkumisega või koduloomadest lammaste, sea, lehma, eriti aga kassi ja koera häälitsuste järeletegemine, sest nemad olid oma huvitava käitumise ja otsekui arusaava vastamisega paluvad partnerid. Narrimise peale kallaletungiv sokk, oinas ja kuri kukk on pajatuste tegelased ning lapsepõlvelugude humoorikad teemad.

Loodushäälendite puhul oli oluline esitada minimalistlik verbaalne tekst looma häälitsusele sarnase tempo ja intonatsiooniga (Siit, siit metsast ei vii mitte üks pirrutikk! - Metsvint). See liik on filoloogilisest seisukohast põhjalikult uuritud: Eduard Laugaste on 1931. aastal avaldanud rahvusvahelisele kasutajale orienteeritud saksakeelse tüübiloetelu koos eessõnaga, samuti monograafilisi uurimusi linnuhäälendite kohta (Laugaste 1931a, 1931b, 1932, 1935). Selgelt eristuva meloodia ja tempoga laululindude laulud on olnud eeskujuks kümnete erinevate laiemalt levinud variantide loomiseks (pääsuke, ööbik, pasknäär, tihane jpt), osal tekstitüüpidel on kindel levikuareaal ja osa kattuvad sisult skandinaavia traditsiooniga. Vaimukas tähenduslik tekst aitas lindu iseloomustada, samas kui tekstide kultuurilised seosed nt legendidega olid ununenud juba 19. sajandil. ${ }^{6}$

Loomadega suhtlemist kajastavad veel karjaselaulud ja -kutsungid, millega anti loomadele ja karjusele märku koju tulemiseks, eriti palju kasutasid karjused neid omavaheliseks suhtlemiseks (vt muusikalist analüüsi Vissel 1986). Kutsungid ja karjaserepertuaar olid igapäevases majanduspraktikas osa inimestevahelisest ja inimene-loom kommunikatsioonist. Vokaalpalade kõrval levisid tähenduseta sõnade või napi tekstiga karjaselaulud. Kutsungid esitati sageli erilise kiirema ja kõrgema intonatsiooniga, kasutati pehmendavaid, 
deminutiivseid, tänaseks üksnes lastekeeles või lastele suunatud tavakõnes säilinud loomanimetusi. vissi - lehm; notsu, kossu, kotsu - siga; kiisu, miisu kass, ute - lammas; tibu - kana, kukk. Kutsudes korrati loomanime mitu korda: kiss-kiss; kutsu-kutsu, kutsa-kutsa. Usundiliselt kriitilistes situatsioonides (vastavalt siis ka usundilistes ja fiktsionaalsetes rahvajuttudes), aga ka väikelastele suunatud kõnes võidi nimetus asendada hoopis onomatopoeetilise häälitsusest tuletatud nimetusega (nt mää - lammas; auh, aua - koer: nurr - kass) või ühendada mitu nimetust (vissi muu, ute mää - ühendus deminutiivsest ja onomatopoeetikal põhinevast nimetusest).

19. sajandi pärimuses reflekteerivad ka usundilised normid: põhjalik sõnakeeldude süsteem ehk otsesõnu ja nimetsi loomadest rääkimist piiravad käsud kehtisid kalastamisel, kus kasutati kalurite salakeelt ja eufemisme pärisnimede ja otse nimetamise asemel (Loorits 1939), nagu ka küttimisel, oluliste tööde alustamisel, enne looma tapmist ja toidulauas. Sellise käitumisviisi paljude praktiliste ja religioossete seletuste hulgas on näiteks kausaalne põhjendus, et hoolikas sõnamaagia järgimine takistab metsloomade sigimist ega meelita neid ligi. Püsifraasidena (nt Kus hundist juttu, seal hunt aia taga) on osa keeldusid keeles säilinud tänaseni. Kogu käitumisviisi taga on rahvapärane filosoofia, et loom kuuleb jutu ära ja saab sellest aru.

Traditsioonilistest loomadega suhtlemise liikidest loitsudega sai linde ja loomi eemale peletada, kurja loomaga (tige koer, hunt, karu, uss) hakkama saada, tüütutest putukatest ja söödikutest (kirp, prussakas, lutikas, kilk) vabaneda. Loitsusid kasutati ka juhul, kui haiguse etioloogia oli seotud konkreetse loomaga. Neis sõnades pöörduti haigust tekitanud looma või linnu poole ja paluti tal haigus ära viia. Osa loitse põhines vanal sümboolse ravimise võttel: haigus kanti üle linnule, loomale, kivile või puule. Tuntud valuvõtmissõnades saadetakse haigus lindudele:

Valutavat kõhtu arstitakse pitsitamise läbi, kusjuures öeldakse:

Harakale haigus,

varesele valu,

mustalinnul muu tõbi,

meie N.N. kõtt [kõht] saagu terveks (E 902 (17) < Suure-Jaani khk Ernst Saabas (1893)).

Loitsudes kasutatakse meelitamiseks veel metafoore ja ümberütlevaid poeetilisi pöördumisi. 


\section{Inimeste ja loomade kommunikatsioon uuema pärimuse valguses}

Vene-Jaapani sõjaga alanud moderniseerumisprotsess ja kiire urbaniseerumine saavutas läbimurde 1905. aasta revolutsiooniga ning mõjutas tugevasti folklooriliikide koosseisu ja nende positsiooni üldises pärimuspildis. Muutuste tõttu arhaiseeruva rahvaluule puhul tõusis küsimus, kas ja missugustel tingimustel saab see püsima jääda. Kas tekstides või esitusviisis on esteetiline, eetiline või usundiline sõnum, mis aitab püsida repertuaaris ka funktsiooni ja miljöö toetuseta? Osa arhaiseeruvast folkloorist nihkus funktsioonivahetusega sekundaartraditsiooni, adapteerus ja mugandus. Näiteks linnulauluimitatsioone kasutati pedagoogikas (avaldati algklasside lugemikes, õpetati lasteaedades) ja avalikel üritustel (näitleja Laine Mesikäpp põimis neid virtuosses esituses suurte üldlaulupidude avatseremooniatesse). Sekundaartraditsiooni kandusid ka karjasehüüded, -huiked ja kutsungid, ehkki nende uus kasutusala oli (arvatavasti verbaalse külje nappuse tõttu) ahtam.

Sotsiaalkultuuriliste ja elulaadi muutuste tõttu ülendusid loomadega seotud lühemad igapäevalood ehk isikujutud, suulise ajaloo joontega ja käibetõdedele lähedased narratiivivormid kultuuriliselt oluliste sõnumite kandjateks. Igapäevalugude vormi on kätketud ka teated ja uskumused loomade võimest inimkeelt mõista või arukalt käituda. Neist lugudest peegeldub kogu verbaalse kommunikatsiooni mitmekesisus: jutuajamine, käsud ja keelud, suhtlemine kui sõbra, kaaslase, lemmiku, treenitava, käsualuse ja töötajaga või lihtsalt koduloomaga.

Eestlastest jahimeeste kui ühise harrastuse kaudu seotud rühma folkloor on uue pärimuse näide. 20. sajandil kasutasid nad ühelt poolt varasemaid jahihüüde, omavaheliseks suhtlemiseks signaale, märguandeid jahikoertele ja teiselt poolt arendasid uusi jahimehejutte - tekkis folkloori kasvukeskkond. Koerte ja hobuste puhul on olnud oluline nende dresseerimine, et õpetada neid alluma teatud signaalidele ja käskudele. Eelmisel sajandil kujunes see kultuuri dikteeritud tingimuseks, mis arenes lemmikloomakultuuriks ja sellega tihedalt seotud folkloori keskkonnaks (vt Eesti kohta Vesik 2008). Koolipärimuse vastustest ilmneb, et lemmikloomadega tegelemine on lastel oluline kodune kohustus.

Koera ja kassi kasvatamine. Kassi ma tegelikult eriti ei kasvata, ta on isepäine. Koera treenin ma näituste jaoks. Koeraga olla on alati omamoodi naljakas, sest ta on põmmpea [---] (EFA, KP 2, 121 (1c) < Tallinn Helena Pruuli, 15 a (2006)). 
Minu hobi on lemmiklooma pidamine. Ma mängin temaga, puhastan puuri, vahetan vett, annan talle sü̈̈a. Ükskord meil jäi rotipuuri uks lahti ja ta jooksis pesukappi. Kui mu vend koju tuli, siis ta ehmatas ära, et rott on ära jooksnud. Kui vend vaatas pesukappi, siis rott magas riiete vahel (EFA, KP 3, 36 (1c) < Tallinn - Anna Hiob, 11 a (2006)).

Perekonna-, sõpruskonna- või ametipärimusena levinud, nagu ka isiklikel kogemustel põhinevad loomajutud kajastavad jutustamist ja mäletamist väärivaid juhtumusi ning katavad enamiku looma elukaarest (vt Villandi 2007). Kuigi lugude esteetiline väärtus ei ole reeglina kõrge, on need jutud minapildi osa ja sellisena tähtsad loomaomanikule, ent stereotüüpsete joonte tõttu kuulatavad teistelegi. Enamasti situatiivsed lood jäädvustavad humoorikad või koomilised igapäevajuhtumid, jutustavad loomadest-selgeltnägijatest või abilistest, nende truudusest ja kangelaslikkusest, pättustest ja nutikusest, haigustest ja vanadusest. Diskursusesse mahub üleloomulikkus (nt klassikalise kodukäija raamis loomad-kodukäijad) ja loomatavand. Kuigi ligilähedaselt samu teemasid leidub varasemates kirjapanekutes, on nende sotsiaalne keskkond erinev. Kõrg- ja keskklassi jõukamat osa puudutavast pärimusest on lood liberaliseerunud linna ja maa keskklassi ja sinikraede tavajuttudeks, tõuloomade puhul on muutunud ka etniline taust. Ühtlustumine on toimunud sotsiaalsete rühmade kõrval ka etniliste rühmade vahel - tõu- ja lemmikloomakultuur on omane kõigile rahvusrühmadele. Niisiis on kadunud eristus baltisakslased ja mõisnikud versus eestlased koos teiste rahvusrühmadega. ${ }^{7}$ Praeguses lemmikloomakultuuris on pigem märgatud eestlaste suuremat konservatiivsust uuenduslike nähtuste, nagu kalmistukultuur vastuvõtmisel, võrreldes venelaste ja Eestisse hiljuti ümberasunud välismaalastega (Kõivupuu 2004: 74; skandinaaviamaade konteksti kohta vt Gustavsson 2008).

Klassikaliste rahvajuttude hääbudes on igapäevased loomajutud hõlvanud traditsioonis suurema ala, sest tegemist on ühise neutraalse või isegi emotsionaalselt soodsa teemaga. Loomakultuur põhineb sotsiaalsel sidususel ja selle juures on minu arvates tähenduslik just kommunikatsiooni emotsionaalne külg, sh võimalused vähendada kõrvaletõrjutuse tunnet. Viimasel poolsajandil on lemmikloomakultuur olnud pidevalt muutuv protsess, kus on muutunud kodus kasvatatavate loomaliikide valik, kogu diskursusesest on saanud ühiskonna laiem aruteluteema.

Küsitluse vastused ja narratiivid peegeldavad erinevaid käibetõdesid loomade keeleoskuse ja keelekäitumise kohta: loom on kurb või taibutu, kui ta kaotab harjumuspärase keelekeskkonna. Näiteks venelaselt ostetud koer on aeglase taibuga, sest ei oska hästi eesti keelt. Samasse liiki kuuluvad spontaansed hinnangud teisest rahvusest naabrite loomade kohta: nii palju saab koer eesti keelest aru küll, et käsku käia. Keelekäitumise erijuhtumite hulka 
kuuluvad looma premeerimised ja karistamised. Sagedasti karistatakse või pragatakse loomaga tema "esimeses keeles" - venelaselt ostetud koeraga vene keeles, soomlaselt ostetud koeraga soome keeles.

Loomadega võidakse rääkida võõrkeeles aga hoopis kindla keele harjutamiseks. Sellise diskursuse näide on minu peretraditsiooni kuuluv lugu salakaubana üle Vene piiri toodud vepsa kassipojast, kes omaniku välitööde ajal kuu aega meil elas. Kuna kassiga räägiti tema kodus vepsa keeles, siis seletasime tema suurenevat nukrameelsust vale keelekeskkonnaga. Rõõm perenaise naasmise üle üksnes tugevdas seletust. Analoogiliselt käsitleb üks uutest juttudest Riia loomaaia kurvameelse elevandi juhtumit. Isu ja tuju kaotanud elevandile kutsuti hädaga talitajaks indialane. Elevandi tervis paranenud tuttavat keelt kuuldes kiiresti.

Lemmikloomaga võidakse suhelda tema päritolukeele asemel enamuskeeles. Näiteks diasporaaeestlased räägivad loomaga tihti asukohamaa riigikeeles. Motiiviks võib olla looma parem arusaamine käskudest ja üldine heaolu, kuid ka automatism - loomaga seotud koolitus, suhtlemine väljaspool oma kodu piire ja üldine keskkond soosib enamuskeele kasutamist. Võimalik, et väliseestlaste puhul piirab eesti keeles suhtlemist vastava allkeele piiratud oskus. Kümne aasta eest külastasin Rootsis Malmös rahvusradikaalist (nagu paljud Teise maailma sõja keeristes kodumaalt lahkunud eestlased) sõpra. Vanadaamil oli kaks kassi, kellega ta suhtles eranditult rootsi keeles, ehkki tema eesti allkeelte oskus oli laitmatu. Suhtluskeel arvestas võrdse vestluskaaslasega, võib-olla kasutati rääkides veidi lihtsamaid ja lühemaid lauseid. Minu küsimusele "Miks sa räägid kassidega rootsi keeles?" vastas ta: "See on kassidele kasulikum, nad saavad paremini hakkama." Mäletan tänaseni hämmastust mõnevõrra patroneeriva vastuse üle, mis põhines uskumusel, et isegi nii sõltumatul loomal nagu kass on tarvis rootsikeelset keskkonda. Peamiselt üllatas aga keeleandeka naise hinnang kassi keeleõppimisevõime kohta: suudab korralikult omandada ühe keele.

Eelnevad juhtumid põhinevad mõttekäigul, et loomad saavad hästi aru keelest, mille keskkonnas nad on üles kasvanud. Koodivahetust kasutatakse, et loom ei saaks jutu sisust aru või juhul, kui on vaja varjata oma plaane. Koeraomanikele on tuttav, kuidas ütluse 'hakkame küüsi lõikama' peale hajub sõber vaikselt ära. Sage motiiv räägib, kuidas perekond kasutab koera ees salatsedes võõrkeelt, aga kuna koer õpib kiiresti ära kriitilised sõnad (sõitma, maale, söök, küünte lõikamine, vannitamine, kammimine jm), on pererahvas sunnitud valima uue keele. Koodivahetuse kasutamisest teenistusülesannete huvides räägib narratiiv USA politseikoertele ungari keeles käskude jagamisest.

[---] Paul Mulick kirjutab: "Springfieldi politseijaoskonna ametlikus juhendis on kaks lehekülge trükitud ungari keeles. Ülejäänud raamat on 
inglise keeles. Springfieldi politseijaoskonnas ei oska mitte keegi ungari keelt. Tegelikult ei oska mitte keegi kogu Springfieldi linnas ungari keelt. Miks sisaldab ametlik politsei käsiraamat kahte ungarikeelset lehekülge? Vastus on, et ungari keel valiti välja just sellepärast, et mitte keegi ei oska ungari keelt. Kas sa mäletad, kuidas mõne aja eest sina, Berman ja mina käisime Washingtonis. [---] uurija ütles, et koer saab ainult prantsuse keelest aru. Politsei käsiraamatus on ungarikeelsed leheküljed, sest politseikoer oskab üksnes ungari keelt. Selleks on kaks head põhjust. Esiteks neid ilmselt treeniti Ungaris. Ja teiseks saab käskusid jagada üksnes koerajuht. Keegi teine ei saa koeral käskida istuda, seista, ennast veeretada või surnut teeselda (Car Talk 200342).

\section{Diskussioon ja kokkuvõte}

Folkloristil on tavaks selekteerida sotsiaalselt sidusast kommunikatsioonivoost teatud osad oma uurimisteemaks. Seekordne väljalõige aitas jälgida loomainimese kommunikatsiooni kajastamist rahvaluuleliikides ja vastajate väljendatud stereotüüpe, eelarvamusi ja igapäevast kommunikatiivset käitumist. Rahvaluuleliigid omandavad ja kaotavad sotsiaalses keskkonnas oma tähenduse. Artiklis käsitletud rahvaluuleliikide osas ennustas Edurd Laugaste juba 1931. aastal linnulauluimitatsioonide hääbumist (Laugaste 1931a) ning see ongi nihkunud institutsionaliseeritud õppekavadesse ja harrastusrühmade repertuaari, nagu ka osa karjasepärimusest. Osa pärimusliikidest on leidnud tee professionaalsesse kunsti: loitsud harrastus- ja new age'i rühmade pärimusse, neošamaanide lavastatud rituaalidesse, kuid ka professionaalsete muusikute loomingusse. Klassikalised rahvajutudki on hääbumise järel siirdunud professionaalide esituskavadesse või lapsevanemate enamasti meediast õpitud repertuaari. Paljude eespool esitatud seikade, tendentside ja jutumotiivide saatus muutuvas ühiskonnas ja folklooris on lahtine. Need on omaette uurimisteemad, kuid kaheldamatult toimib Laozi reegel, mille järgi kõik kulgeb ja muutub, et vastata paremini ideaalile (Lao Tzu 1916: 29). Küll aga iseloomustab konvergents, tänase folkloori põhijoon, ka loomapärimust. Suhteliselt muutumatuna on püsinud üksnes lihtsad vanad universaalsed suhtlusvõtted (vilistamine, tänapäevastatud signaalid ja kutsungid), telepaatiline suhtlemine.

Loomapärimus (eriti jutud) laseb meil näha erinevaid emotsioone ja omavahelise kommunikatsiooni võtteid, mis juhivad meid tagasi küsimuse juurde, mis muudab inimese ja looma suhtlemise tähendusrikkaks.Võime õigustatult pärida, mida edastatakse nende lihtsate ja armsate, mitte just virtuoossete, kuid igapäevaste lugudega? Miks nad on meile vajalikud? Mis on nende sõnum 
meile? Põhjuseks ei ole ju ometi üksnes suhtlemistõrgete ületamine ja jutujätkuks neutraalse teema arendamine?

Leidnud end folkloristlike seletusviisidega ummikus olevat, pöördusin psühholoogia ja filosoofia poole. Tänapäeva inimesed on haaratud üleilmastumise ja stabiilsust tagava turvalise lokaalsuse vastuolulisse duaalsusse, mis mõjutab ka käsitletavat teemat ehk inimeste ja loomade kommunikatsiooni. "Ise on haaratud globaliseerumisprotsessi kiirliikumisse ja muutustesse, kuid samal ajal vajab ta sügavalt lokaalset stabiilsust" (Chandler \& Lalonde \& Sokol $\&$ Hallett 2003). Loomad esindavad lokaalset stabiilsustunnet. Loomad on aegade jooksul hoidnud meid paiksena, loonud paiksuse ümber miljöö ja atmosfääri, mida me tihti täpselt ei analüüsi ega sõnasta. Kuulsa ärkamisaegse luuletaja Lydia Koidula "Meil aiaäärne tänavas" räägib lapsepõlvekoduga seotud ootustest ehk inimese seest lähtuvast nostalgilisest maailmaavastamise tundest. Arvatavasti kuuluvad nende ridadega kaasnevasse mentaalsesse mälupilti ja tundesse hobuse pehmed mokad ja kassi päikesesoe külg, võib-olla sea sügamine või linnupoja pekslev süda, ehkki luuletus neid otsesõnu ei puuduta. Need on ridade vahel, nagu tänase perekonna koduroti või -jänesega seotud mured ja rõõmud, osa sõnadesse valamata kodutundest.

Ühiskondlike ootuste ja lubatavuste ahel mõjutab tugevasti meie käitumist. Tänapäevane sotsiaalne keskkond ei salli üldiselt emotsioone ja nende väljendamist. Psühholoog James R. Averill väidab, et emotsioonireeglid aitavad luua emotsionaalsete rollide võrgustiku või teisisõnu emotsionaalsed positsioonid. Emotsionaalne positsioon on analüüsitav privileegide, piirangute, kohustuste ja vastuvõtutingimuste kaudu (Averill 1997). Filosoofide Hubert Hermansi ja Giancarlo Dimaggio (2007) arvates on isiksuse seisukohast tähelepanuväärne, et inimestel on sõltuvalt oma positsioonist teatud emotsioonide väljendamine teatud situatsioonis lubatud, samal ajal eeldatakse, et nad teisi emotsioone ei tohi näidata või need tuleb alla suruda. Kogu inimkäitumine on piiratud emotsionaalsete standarditega.

Suhetes loomadega saame kasutada emotsioone palju vabamalt, need on vähem kontrollitud ühiskondlikest normidest, neid väljendatakse eraldatud, isiklikus ruumis, kus saame oma emotsionaalsed positsioonid ja rollid ise määrata ega pea alluma sootsiumis kujunenud normidele.

Loomadega suhtlemisel on oluline aspekt erinevate kommunikatsiooniliikide kombineerimine: verbaalse suhtlemise kõrval kasutatakse mitteverbaalset suhtlemist. Sotsiaalantropoloog Tim Ingold (1988) on koguni juhtinud tähelepanu verbaalse suhtlemise ületähtsustamisele, mis vastab kindlasti tõele. Suhtleme omavahelgi palju laiemalt kui üksnes sõnadega. Inimese-looma kommunikatsiooni puhul on mitteverbaalsel suhtlemisel määratu tähtsus. Puudutamine, kehasoojus, lähedus, jälgimine jm erinevate meeltega vastuvõetavad 
signaalid ja märgid ning neist lähtuvad tunded ja mõtted on tähtis kommunikatsiooni osa. Selliste suhtlusvormide voorustele ja kommunikatsioonitulemuste tõeväärtusele juhivad tähelepanu mitmed uurijad (Tuan 1984; Raupp 1999).

Universaalsete mitteverbaalsete signaalidega (vilega kutsumine ja peletamine, häälitsuse imitatsioonid), suhtlemine on kiire, neid on lihtne kasutada, nad levivad paremini, nad eksitavad vähem, on ühesema semantilise tähendusega, mistõttu nad on säilitanud oma aktuaalsuse. Ka varasemast folkloorist tuttavad kutsungid, sh lastekeelde taandunud liiginimede ja asendusnimede kasutamine on ühemõtteline suhtlemisvõimalus, mille mõistetavust suurendavad intonatsioon, esitustempo jt kvaliteedid.

Põhimõtteliselt näivad inimeste ja loomade kommunikatsiooni juures kehtivat samad mudelid, mis suunavad erinevate keelte, ka standardkeele ja allkeelte koodivahetusele (Crystal 1987). Sellega kompenseeritakse ühe keele puudujäägid kommunikatsioonivahendina, koodivahetus aitab edastada hoiakuid ja saavutada erilise efekti.

\section{Kommentaarid}

1 Artikkel on valminud sihtfinantseritava teema SF0030181s08 raames.

2 Statistika järgi ostab Suurbritannias $60 \%$ üksikutest inimestest lemmiku endale seltsiks, looma soetamise juures on üldse esikohal seltsilise või sõbra leidmine, ligikaudu 5\% kassidest valis ise omaniku.

${ }^{3}$ Vrd PetNeti statistikat: $91 \%$ omanikest väidab, et nad on oma lemmikuga väga lähedased, lemmikloom on pereliige (PetNet 2008).

${ }^{4}$ Umbkaudu 130 vastanut vanuses 15-70 aastat, lähem analüüs keelevastuste kohta koostamisel.

5 Vaatluse all ei ole fiktsionaalsusel põhinevad muinasjutud-müüdid-muistendid, kus esineb tavaline dialoog loomadega või mis põhinevad imevahendite abil loomakeele oskuse omandamisel ja selle läbi erilistele teadmistele ligipääsemises. Ka loomade peremehed-nõiad (hundiperemehed, ussisõnade teadjad jt) ei ole seekordse käsitluse teema.

6 E. Laugaste osutab pääsukeselaulu seosele pühakulegendiga (Laugaste 1932).

7 19. sajandi olustikus olid lemmikloomalood seotud ennekõike mõisakultuuriga, millele ennast vastandati. Sama peegeldub rahvajuttudest, kus loomale rajatud hauasammas või mälestusmärk, uhke matusepaik jm privileegid pälvisid tähelepanu kui teise rühma veidrused või pahed. 


\section{Arhiiviallikad}

\section{Eesti Rahvaluule Arhiivi kogud}

E = Matthias Johann Eiseni rahvaluulekogu), 1880-1934 ja mõned varasemad tekstid

$\mathrm{EFA}, \mathrm{KP}=$ Eesti folklooriarhiivi rahvaluulekogu, Eesti Rahvaluule Arhiivi kogu peamiselt alates 1996. aastast, koolipärimuse kogumise võistluste materjalid

\section{Kirjandus}

AIR 2007 = Annales of Improbable Research (AIR) 11: 5 (sept/okt 2005) (http:// improbable.com/ig/winners/\#ig2007 - 28. märts 2010).

Averill, James R. 1997. The Emotions: An Integrative Approach. Hogan, Robert \& Johnson, John A. \& Briggs, Stephen R. (toim). Handbook of Personality Psychology. San Diego: Academic Press, lk 513-541.

Baker, Steve 1993. Picturing the Beast:Animals, Identity and Representation. Manchester \& New York: Manchester University Press.

Bradbury, Jack W. 2003. Vocal communication in Wild Parrots. Waal, Frans B. M. \& Tyack, Peter L. (toim). Animal Social Complexity: Intelligence, Culture, and Individualized Societies. Cambridge (Massachusetts): Harvard University Press, lk 293-316.

Car Talk 200342. The Puzzler (http://www.cartalk.com/content/puzzler/transcripts/ 200342/answer.html - 28. märts 2010).

Chandler, Michael J. \& Lalonde, Christopher E. \& Sokol, Bryan W. \& Hallett, Darcy 2003. Personal Persistence, Identity Development, and Suicide: A Study of Native and Nonnative North-American Adolescents. Monographs of the Society for Research in Child Development 273: 68: 2 (http://www.psych.ubc.ca/ chandlerlab/Chandler,\%20Lalonde, $\% 20$ Sokol,\%20\&\%20Hallett\%20(2003).pdf - 28. märts 2010).

Crystal, David 1987. The Cambridge Encyclopedia of Language. Cambridge [Cambridgeshire] \& New York: Cambridge University Press.

Dabbs, Matt 2007. What Language Will We Speak in Heaven? Matt Dabbs’ Blog, pühapäev, 6. mai. Saint Petersburg (Florida) (http://mattdabbs.blogspot.com/2007/05/whatlanguage-will-we-speak-in-heaven.html - 28. märts 2010).

Gustavsson, Anders 2008. Grief at the Loss of a Pet - As Exemplified by the Cat. ARV: Nordic Yearbook of Folklore 64, lk 101-123.

Hermans, Hubert J. M. \& Dimaggio, Giancarlo 2007. Self, Identity, and Globalization in Times of Uncertainty: A Dialogical Analysis. Review of General Psychology 11: 1, lk 31-61 (http://www.socsci.kun.nl/ hermans/100.pdf - 28. märts 2010).

Hymes, Dell 1974. Foundations in Sociolinguistics: An Ethnographic Approach. Philadelphia: University of Pennsylvania Press. 
Ingold, Tim (toim) 1988. What is an Animal? One World archaeology 1. London \& Boston: Unwin Hyman.

Jaago, Tiiu \& Kõiva, Mare (koost) 2002. Dialoog privaatse ja avaliku elu vahel: Inimese ja keskkonna suhete peegeldus pärimuses. Elektrooniline konverents: Täienduskoolituskursus, 18.02-18.05.2002, Tartu. Tartu: Eesti Kirjandusmuuseum \& Tartu Ülikool.

Krikmann, Arvo 2001. Proverbs on Animal Identity: Typological Memoirs. Folklore: Electronic Journal of Folklore 17, lk 7-84 (http://haldjas.folklore.ee/folklore/vol17/ proverbs.pdf - 28. märts 2010).

Kõiva, Mare, ilmumas. Creatures Between Two Worlds. Käsikiri. Tartu: Eesti Kirjandusmuuseumi folkloristika osakond.

Kõivupuu, Marju 2004. Risti peale kirjutas: Ühel papil oli peni... Eesti loomakalmistukultuurist. Mäetagused 25, lk 47-76 (http://haldjas.folklore.ee/tagused/nr25/ loomakalmistud.pdf - 28. märts 2010).

Lao Tzu (= Laozi) 1916. Tao Teh King. A Tentative Translation from Chinese by Isabella Mears. Glasgow: William McLellan \& Co.

Laugaste, Eduard 1931a. Die estnischen Vogelstimmendeutungen. Folklore Fellows Communications 97. Helsinki: Suomalainen Tiedeakatemia.

Laugaste (Treu), Eduard 1931b. Välismõjudest eesti pääsukeselauludes. Eesti Kirjandus 10, lk 506-519.

Laugaste, Eduard 1932. Ööbiku laul. Vanavara vallast. Õpetatud Eesti Seltsi Kirjad 1. Tartu: Õpetatud Eesti Selts, lk 120-152.

Laugaste, Eduard 1935. Peoleo-laulu suhteist. Kaleviste mailt. Õpetatud Eesti Seltsi Kirjad 3. Tartu: Õpetatud Eesti Selts, lk 108-122.

Lee, Chang-Hsing \& Chou, Chih-Hsun \& Han, Chin-Chuan \& Huang, Ren-Zhuang 2006. Automatic recognition of animal vocalizations using averaged MFCC and linear discriminant analysis. Pattern Recognition Letters Archive 27: 2, lk 93-101.

Loorits, Oskar 1939. Gedanken-, Tat- und Worttabu bei den estnischen Fischern. Eesti Rahvaluule Arhiivi Toimetused 9. Tartu: K. Mattiesen.

Manning, Aubrey \& Serpell, James A. (toim) 1994. Animals and Human Society: Changing Perspectives. London: Routledge.

Peterson, Aleksei \& Proodel, Mall 1968. Jahipidamisest ning metsloomadest Eestis etnograafi ja folkloristi pilguga 8. Põder. Põder rahvatraditsioonis. Eesti Loodus 11, lk 648-654.

PetNet 2008. Pet Statistics: Pet Ownership in Australia. PetNet (http://www.petnet.com.au/ pet-statistics - 28. märts 2010).

pmfa 2008. Owernship Trends 08. pfma. Pet Food Manufacturers' Assotiation. (http:// www.pfma.org.uk/overall/pet-pop-08.htm - 28. märts 2010).

pmfa 2009. Pet Population Figures 09. pfma. Pet Food Manufacturers' Assotiation (http://www.pfma.org.uk/overall/pet-population-figures-.htm - 12. november 2009, praeguseks andmed muudetud). 
Presnakova, Irina 2010. Representation of Animals in Victorian Ghost Stories. Stašulāne, Anita (toim). Kultūras studijas: Zinātnisko rakstu krājums = Cultural studies: Scientific papers II. Animals in Literature and Culture. International Scientific Conference XIX Scientific Readings. Daugavpils: Daugavpils Universitātes Akadēmiskais apgāds Saule, lk 103-113.

Prucha, Jan 1983. Using Language: A Sociofunctional Approach. Bain, Bruce (toim). The Sociogenesis of Language and Human Conduct. New York: Plenum Press, lk 287295.

Raupp, Carol D. 1999. Treasuring, Trashing or Terrorizing: Adult Outcomes of Childhood Socialization with Animals. Society \& Animals. Journal of Human-Animal Studies 7: 2, lk 141-159 (http://www.societyandanimalsforum.org/sa/sa7.2/Raupp.html - 28. märts 2010).

Reiss, Diana \& McCowan, Brenda \& Marino, Lori 1997. Communicative and Other Cognitive Characteristics of Dolphins. Trends in Cognitive Science 1: 4, lk 140-145.

Rendell, Luke 2006. Variation and Cultural Transmission of Sperm Whale (Physeter macrocephalus) codas (http://whitelab.biology.dal.ca//r/atc.htm - 28. märts 2010).

Rendell, Luke E. \& Whitehead, Hal 2001. Culture in Whales and Dolphins. Behavioral and Brain Sciences 24: 2, lk 309-382 (http://whitelab.biology.dal.ca//r/culture.pdf - 28. märts 2010).

Serpell, James A. 1996. In the Company of Animals: A Study of Human-Animal Relationships. Cambridge \& New York: Cambridge University Press.

Smith, Penelope 1997. Animal Talk (http://www.animaltalk.net/ - 28. märts 2010).

Toro, Juan Manuel \& Trobalon, Josep B. \& Sebastián-Gallés, Núria 2005. Effects of Backward Speech and Speaker Variability in Language Discrimination by Rats. Journal of Experimental Psychology Animal Behavior Processes 31: 1, lk 95-100 (http:// www.apa.org/pubs/journals/releases/language-discrimination.pdf - 28. märts 2010).

The Humane Society 2008 = The Humane Society of the United States. U.S. Pet Ownership Statistics, 17. märts 2008 (http://www.hsus.org/pets/issues_affecting_our_pets/ pet_overpopulation_and_ownership_statistics/us_pet_ownership_statistics.html - 17 . september 2009, praegu andmed muudetud, kuid endisel kujul kättesaadavad nt aadressil http://www.healthyhalopets.com/pet-education/pet-facts.html - 28. märts 2010).

Tuan, Yi-fu 1984. Dominance and Affection: The Making of Pets. New Haven: Yale University Press.

Uljas, Harli 2003. Jaapanlased tõlgivad koerte haukumist. Postimees, 26. märts (http:// vana.www.postimees.ee/index.html?number=764\&op=lugu\&id=94450 - 28. märts 2010). Eesti Patendiameti uudiste arhiiv 2003, 26.03.2003 (http://www.patentlib.ee/ index.php?id=1314 -1. aprill 2010).

Vesik, Liisa 2008. Lemmikloomad Eesti veebis viimasel viiel aastal. Mäetagused 40, lk 70-82 (http://www.folklore.ee/tagused/nr40/vesik.pdf - 28. märts 2010).

Villandi, Maarja 2007. Peaaegu nagu inimene. Miks ja mida räägitakse lemmikloomadest. Mäetagused 31, lk 108-130 (http://www.folklore.ee/tagused/nr31/maarja.pdf 28. märts 2010). 
Vissel, Anu 2002. Estonian Herding Songs from the Perspective of Ethnic Relations. Boiko, Martin (toim). Traditional Music in Baltic Countries. Berlin:Verlag Wissenschaft und Bildung, lk 79-105.

Wheelock, Wade T. 1987. Sacred Language. Eliade, Mircea (toim). Encyclopedia of Religion 8. New York \& London: Macmillan, lk 439-446.

\title{
Summary
}

\section{What language do we use with pets?}

\author{
Mare Kõiva
}

Key words: animal stories, human-animal communication, pet culture, zoofolklore

Changes in the socio-cultural and economic sphere are reflected in folklore by the rise of certain stereotypes, beliefs, prejudices and types of narratives. The increase in the number of pet animals gives us reason to view the defining features of human-pet communication as well as language use. The article considers these aspects based on archival folklore material and questionnaire results. In addition to usual or slightly simplified talk, pet-owners also employ kid-speech and even a change of code. The change of code conveys attitudes and helps attain a desired specific effect (praise, condemnation, subjugation). Non-verbal communication also has an important role, both on its own and in combination with other modes of communication.

Folklore genres, reflecting the communicating situation, include universal paraverbal signals (calling by whistling and warding, imitating voices) and simple calls, such as instrumental, whistled and voice signals. Complex poetic texts (natural sounds, herdsman's cries and calls; verbal magic aliases, incantations) have, over time, become part of the institutionalised folklore movement or professionals' repertoire. Folklore genres increasingly include personal experience narratives - narratives of a simple form that carry culturally significant messages.

These narratives also exhibit beliefs of the animals' capability of understanding human speech and acting with reason. The functions of these stories include creating a sense of local stability. The importance of verbal communication within a society has formed together with rules of conduct - limits on emotional standards and positions. Communication with a pet gives us more freedom to use emotions and determine our role. Contemporary pet culture includes technological translation devices and a developing profession - telepathic translators - illustrating the need to understand the messages the other side is sending. 